Departamento de Historia Universidad de Santiago de Chile

Revista de Historia Social y de las Mentalidades

Volumen 24, $\mathrm{N}^{\circ}$ 1, 2020: 109-146

Issn On Line: 0719-4749

\title{
ESTUDIANTES E IZQUIERDAS. REFLEXIONES SOBRE LOS FONDOS PERSONALES DE LA REFORMA UNIVERSITARIA*
}

\author{
STUDENTS AND LEFT. REFLECTIONS ON THE PERSONAL FUNDS \\ OF THE UNIVERSITY REFORM
}

\author{
DRA. NATALIA BUSTELO** \\ CONICET-CeDInCI-UNSAM \\ Buenos Aires, Argentina \\ Email: nataliabustelo@yahoo.com.ar \\ Id-ORCID: 0000-0001-5209-0333 \\ MARÍA EUGENIA SIK \\ CeDInCI-UNSAM \\ Buenos Aires, Argentina \\ Email: eugenia.sik@gmail.com \\ Id-ORCID: 0000-0003-2539-6841
}

\begin{abstract}
RESUMEN
El artículo se inscribe en el cruce entre historia y archivística que viene impulsando el Centro de Documentación e Investigación de la Cultura de Izquierdas (CeDInCI, Buenos Aires, Argentina). Comienza por reconstruir las problemáticas teóricas y metodológicas ligadas a un tipo particular de archivos: los fondos personales. Luego se detiene en las características de los documentos relativos a la Reforma Universitaria, esto es, al movimiento estudiantil que estalló en Córdoba, Argentina, en
\end{abstract}

\begin{abstract}
The article addresses in the links between history and archival practice promoted by the Centro de Documentación e Investigación de la Cultura de Izquierdas (CeDInCI, Buenos Aires, Argentina). In the first part we reconstruct the theoretical and methodological problems related to a particular type of archives: personal fonds. Then we expose the characteristics of the documents related to the Reforma Universitaria, that is, the student movement that broke out in Córdoba,
\end{abstract}

* Recibido: 2 de marzo de 2020. Aprobado: 24 de abril de 2020.

** Artículo científico. Investigación personal desde una perspectiva multidisciplinaria ya que la co-autora Sra. María Eugenia Sik se desempeña en el área de Bibliotecología y Ciencia de la Información. 
1918 y se expandió en las décadas siguientes por el continente latinoamericano. Finalmente, a partir del análisis de algunos documentos reflexiona sobre el valor histórico y patrimonial que portan los fondos producidos por los animadores argentinos de la Reforma.

Palabras clave: Reforma Universitaria de 1918; fondos personales; archivística; historiografía
Argentina, in 1918 and expanded in the following decades throughout the continent. Finally, from the analysis of some documents, we reflect on the historical and heritage value of the personal archives produced by the Argentine animators of the Reformation.

Keywords: University Reform of 1918; Personal Archives; Archival Studies; Historiography

Cómo citar: Bustelo, Natalia y María Eugenia Sik. (2020). "Estudiantes e Izquierdas: Reflexiones sobre los fondos personales de la Reforma universitaria". Revista Historia Social y de las Mentalidades, 24(1), 109-146. DOI: 10.35588/rhsm.v24i1.4384.

\section{INTRODUCCIÓN}

En las últimas décadas la archivística ha desarrollado líneas de reflexión que ampliaron y enriquecieron sus nociones centrales y sus herramientas de análisis. "Documento" y "fondo de archivo" han dejado de ser nociones centradas en las instituciones para incorporar a las personas que producen y/o ordenan los documentos y fondos. Por un lado, el señalamiento de la inevitable impronta que dejan quienes custodian los fondos ha motivado el análisis de las "lógicas subjetivas". Por otro, a la valoración de los fondos generados por "personajes ilustres" se ha sumado la de los generados por personas con menor o escaso reconocimiento social. En efecto, actualmente se preservan y se abren a la consulta pública fondos con documentos de los que hasta hace poco se discutía su valor histórico y patrimonial.

A pesar de esos desarrollos, tanto en la investigación histórica como en la práctica cotidiana de muchas instituciones que custodian fondos aún predomina una mirada fragmentadora, esto es, los documentos a los que se les asigna un valor mayor tienden a ser desvinculados de su condición de piezas dentro de un conjunto que porta una lógica -cuya dimensión institucional predomina en unos casos y la subjetiva en otros- de producción y organización, y con ello se pierden valores y significados vinculados a esa lógica. Agreguemos a esto que en América Latina estamos lejos de contar con leyes y políticas públicas que aseguren la preservación de la documentación generada por instituciones, y que esa carencia tiene efectos más graves en el caso de los fondos generados por personas. Si no recae sobre estas un significativo reconocimiento social, sigue siendo difícil que las instituciones o entidades consigan los recursos necesarios 
para conservar sus fondos. Paradójicamente, si esas personas cuentan con un importante reconocimiento, la presión mercantil promueve que los fondos sean comprados por instituciones extranjeras con mayores recursos financieros o por diversos coleccionistas privados entre los que los documentos se dispersan y se sustraen a la investigación histórica y al tratamiento archivístico.

En Argentina, el Centro de Documentación e Investigación de la Cultura de Izquierdas (CeDInCI) viene desarrollando una sistemática política de preservación de los materiales políticos, artísticos y culturales vinculados a las izquierdas locales. Desde su fundación en 1998, reúne, cataloga, difunde y estudia los libros, folletos, publicaciones periódicas, fotografías, recortes periodísticos, afiches, volantes, cartas y manuscritos que produjeron $-\mathrm{y}$ continúan produciendo- las más diversas expresiones de las izquierdas argentinas. Esta sistemática política de preservación permite que hoy su biblioteca, hemeroteca y archivo - ubicados en la ciudad de Buenos Aires- ofrezcan a la consulta uno de los acervos más completos y voluminosos sobre el tema. En las décadas anteriores, las investigaciones sobre la cultura de izquierdas latinoamericana tenían su acervo público privilegiado en el Instituto de Historia Social de Amsterdam. Hoy, además del CeDInCI, se han abierto otras instituciones que custodian fondos de ese tipo en América Latina y entre ellas se destaca el Arquivo Edward Leuenroth de la Universidad de Campinas. En Perú, el archivo personal de José Carlos Mariátegui provee acceso digital a epistolarios y colecciones hemerográficas, además de avanzar con herramientas informáticas de análisis de redes, a la vanguardia de las potencialidades de un archivo como el de un intelectual con una gran gravitación latinoamericana. En cuanto a la Argentina, contamos con el área de Archivos y Colecciones Particulares de la Biblioteca Nacional de la República Argentina, la Asociación Civil Memoria Abierta de Buenos Aires, el Fondo de Gregorio Bermann y el Fondo de José "Pancho" Aricó, ambos dependientes de la Universidad Nacional de Córdoba, la Universidad Popular Alejandro Korn de La Plata y la biblioteca y archivo histórico de la Unión Cívica Radical. Además, algunas bibliotecas anarquistas, socialistas y comunistas comenzaron a poner a la consulta algunos de los fondos personales que conservaban.

En cuanto a los aportes históricos basados en esos archivos, el CeDInCI desde su condición de centro de investigación viene impulsando una renovación historiográfica orientada no solo por la historia social y cultural de las izquierdas y los movimientos sociales, sino también por el giro material y, más específicamente, por la historia intelectual y de los/as intelectuales y por la historia del libro y la edición. Para promover una reflexión transdisciplinaria sobre las instancias de investigación y las políticas de archivo, biblioteca y patrimonio 
documental, sus investigadores han construido diversas instancias. Además de editar varias guías de fondos de archivo del CeDInCI y una bibliohemerografía y guía de fuentes sobre el anarquismo argentino (Domínguez Rubio), vienen seleccionando, traduciendo y publicando artículos y dossiers temáticos en Políticas de la memoria, el anuario del CeDInCI, y vienen organizando, desde 2000, las Jornadas de Historia de las Izquierdas. A ello se sumaron en 2015 las I Jornadas de Reflexión sobre la Construcción del Archivo, convertidas en 2017 en el $\mathrm{I}^{\mathrm{o}}$ Congreso Internacional sobre Archivos Personales (http:// jornadasarchivos.cedinci.org). Asimismo, en 2017 se fundó el "Programa de Memorias políticas feministas y sexo genéricas" con el fin de preservar, valorar y reflexionar sobre los fondos de archivos vinculados a esas memorias (Fernández Cordero) y actualmente se prepara el Diccionario Biográfico de las Izquierdas Latinoamericanas (DiBILa) (http://diccionario.cedinci.org).

Las páginas que siguen recogen esas diversas iniciativas y reflexiones sobre el cruce entre historia y archivística impulsadas por el CeDInCI para detenerse en el valor de los documentos relativos a la Reforma Universitaria, esto es, al movimiento político-cultural que -surgido en 1918 en la ciudad argentina de Córdoba- durante el siglo XX inscribió la vida estudiantil de América Latina en el campo de las izquierdas. Luego de reconstruir las problemáticas ligadas a los fondos personales, analizamos las características de los documentos sobre la Reforma y el valor histórico y patrimonial que tienen los fondos producidos por los animadores argentinos de la Reforma.

\section{LOS "FONDOS PERSONALES" Y LA ARCHIVÍSTICA CONTEMPORÁNEA}

En la Argentina de las últimas décadas se registra la apertura de nuevos acervos y la convivencia de distintos tipos de instituciones que conservan fondos de archivo (fundamentalmente, centros universitarios, bibliotecas públicas y organizaciones civiles de diverso tipo). ${ }^{1}$ Si bien la mayoría de esos fondos 
fueron generados por instituciones, los trabajos que se vienen presentando en los distintos congresos y publicaciones sobre archivos dan cuenta de la apertura de un amplio universo de fondos de carácter personal.

Este fenómeno local se acompaña de una renovación conceptual de la archivística moderna, estabilizada sobre todo por dos textos fundantes, el Manual de Organización y Descripción de los holandeses Muller, Feith y Fruin (1898) y el Manual for Archive Administration de Hilary Jenkinson (1922). Allí los archivos personales, por un lado, se concibieron dentro de las bibliotecas y las sociedades históricas y, por el otro, se abordaron como una "colección de manuscritos" con rasgos que responderían de modo deficiente a los parámetros de los fondos propiamente dichos, esto es, los que reúnen documentación generada por instituciones.

Si recordamos que el Archivo surge junto al Estado moderno, como el conjunto de documentos que ese Estado genera en su proceso de identificación de los individuos, no sorprende que la archivística haya construido los parámetros de análisis de los "documentos de archivo" desde la atención a rasgos institucionales que suelen estar ausentes en la documentación producida no sobre sino por individuos (Jardim; Swiderski). A ello agreguemos que cuando la archivística moderna se ocupó de los fondos personales, se circunscribió a los generados por "personajes ilustres", sea de la política, las letras o las "bellas artes" (Artières). En efecto, la tradición de los "archivos totales" (total archives), registrada sobre todo en Canadá, promovió que las instituciones archivísticas adquirieran fondos de personas. Pero, como subraya Jennifer Douglas, es indudable la preponderancia de la adquisición de documentos oficiales sobre los personales y su restricción a las personas reconocidas (23-24).

La literatura centrada en los archivos personales comenzó a proliferar en los años noventa en el mundo anglosajón y desde allí se expandió a otras latitudes. Por los mismos años, Terry Cook, Brien Brothman, Verne Harris, Eric Ketelaar, Joan Schwartz, Mark Green, Tom Nesmith y Randall Jimerson, fundamentalmente, conformaron la corriente de archivística posmoderna. Esta continúa discutiendo el encadenamiento del Archivo al Estado, pero además ha puesto en el centro las jerarquías desde las que se atendió a los fondos personales y la neutralidad presupuesta en las tareas archivísticas. Este desplazamiento teórico, objeto de debates en la disciplina (Heredia), insiste tanto en la importancia de los

durante la última dictadura argentina. Y la Resolución ministerial 47/2012, denominada "Plan de modernización de los Fondos Documentales de las Fuerzas Armadas", estipuló el tratamiento archivístico de los fondos del Ejército, la Armada, la Fuerza Aérea y la Escuela de Defensa Nacional. 
fondos generados por los más diversos tipos de personas como en la construcción de herramientas que permitan historizar y analizar las inevitables decisiones subjetivas que porta todo fondo. Y la archivística también se renueva con la reflexión sobre el acceso digital y las nuevas competencias que demandan las tecnologías de la información y de la comunicación. El acceso masivo a Internet y la cantidad inimaginable de información que hoy se encuentra disponible en formato digital podrían ofrecerse no solo a los historiadores, sino también a la ciudadanía en general, como un modo de preservar las memorias. Pero ante esa "abundancia documental" es imprescindible que la archivística desarrolle instrumentos de descripción que permitan búsquedas transversales y recuperen la información contextual y la interrelación entre personas e instituciones. A ello apuntan los estándares propuestos por el Consejo Internacional de Archivos y el sistema de descripción online de fondos Access to Memory -de cuyo uso en Argentina el CeDInCI fue pionero, pues comenzó a utilizarlo en sus fondos en 2012-.

Esos estándares y sistemas de descripción, así como la mencionada corriente anglosajona, apuestan a una homogeneización de los procedimientos de abordaje de los distintos tipos de fondos que no quite valor a los documentos personales producidos por las más diversas personas. Para ello se propone, por un lado, que lo que caracteriza a la archivística no es su relación con las instituciones estatales, sino el tratamiento de la documentación como un "fondo de archivo", esto es, como un "conjunto orgánico de documentos procedente de una institución, colectivo o persona, testimonio o prueba de su respectiva gestión" (Heredia, ¿Qué es un archivo? 30). En oposición a la singularidad del libro para la bibliotecología y a la unidad de la pieza característica de la museología, la archivística parte del fondo de archivo como un todo y aborda el documento como una pieza de ese todo. Esta perspectiva hace foco en la dimensión arqueológica de los documentos, o bien en su contexto de producción y su lógica -institucional y subjetiva- de organización y preservación. Por otro lado, esos fondos institucionales y personales adquieren su valor en tanto piezas de la memoria social y cultural que debe preservarse. Y si algo significativo dejó el debate sobre el inicio de una era posmoderna, es una desjerarquización que impide que al interior de esa memoria se distinga entre documentos preservables y no preservables -lo que, por otra parte, introduce el problema, acrecentado por la era digital, de la potencial extensión infinita del archivo-.

Los tres parámetros con los que la archivística clásica venía pensando los documentos de los fondos y que hoy se ven tensionados al otorgarle la misma jerarquía a los documentos personales y los institucionales son: el carácter 
seriado y singular de los documentos, sus lazos de gestión y la carga jurídica contenida. Si se concede que los archivos pueden provenir de oficinas estatales o de instituciones de salud, educación o trabajo, entre otras, pero también pueden ser generados por personas con una destacada militancia política o social, o por sujetos con una gravitante actividad intelectual o artística, por "gente común", o incluso por "gente abyecta" (Artières), un rasgo compartido por el amplio segundo grupo es que muchos de sus documentos pueden carecer de lazos de gestión y de carga jurídica, pero sobre todo que esos rasgos no se presentan como los más relevantes en su valoración. En los fondos personales, además, el carácter seriado puede ser menos evidente que el entramado orgánico de los documentos institucionales, sea que se trate de la documentación sobre un individuo generada por el Estado a lo largo de una vida o de documentos sobre varios individuos. Desde ya, el carácter seriado es constitutivo de las cartas que contienen algunos fondos personales, pero también se advierte en las facturas de servicios y documentos administrativos que los donantes, archivistas, gestores patrimoniales y otras personas involucradas en los fondos tienden a expurgar incluso muchas veces sin dejar registros de esas decisiones-.

La cuestión de la rendición de cuentas a la ciudadanía (accountability) nos permite trazar otro contraste entre los fondos personales y los institucionales. Estos son -o deberían ser- de libre acceso a los/as ciudadanos/as - con la excepción de la documentación clasificada y con el respeto hacia los datos sensibles-. En cambio, la documentación conservada en los fondos personales, en muchas oportunidades, suele producirse para ser leída únicamente por quien la genera y, eventualmente, quienes sean destinatarios de algunos documentos. Detrás de la apertura pública de los fondos personales no hay, entonces, una obligación fundada en el derecho moderno, sino una voluntad colectiva de inscribirlos como parte del patrimonio público común. Y esa autonomía frente al Estado introduce otros problemas. La decisión de transferir un fondo a una institución y la existencia de instituciones interesadas en albergarlo dependen del crecimiento de una comunidad presente y activa. Un crecimiento del interés que, ante el vacío legislativo y la deficiencia de las políticas públicas y de las prácticas de preservación, debe contrarrestar el incremento de los intentos de compra, venta y desguace discrecional de los documentos de un fondo (Tarcus, "¿El drenaje").

Pero el mayor contraste entre los fondos institucionales y los personales reside, sin duda, en las disciplinas desde las que se analiza la lógica de los documentos. En principio, los fondos institucionales se producen por gestiones reguladas y estandarizadas, y ello lleva a que las ciencias jurídicas ofrezcan una importante herramienta para comprender su lógica. Si bien esa lógica también 
responde a una dimensión subjetiva, sea porque los mecanismos de producción y de guarda no registran la articulación esperada o porque es inevitable que quienes intervienen en la guarda dejen su impronta, en el caso de los fondos personales la subjetividad es mucho mayor y central. De ahí que las disciplinas humanísticas, y sobre todo la psicología, sean las que ofrezcan los abordajes más fructíferos. Precisa Catherine Hobbs:

Los archivos personales, por lo tanto, no son sólo sobre transacciones de negocios personales "oficiales" y actividades formales, sino que también son la fuente más frecuente de comentarios sobre la vida diaria y personal y las relaciones, casi por su propia naturaleza. En líneas generales, el fondo es un sitio donde la personalidad y los eventos de la vida interactúan en forma documental. Ciertamente, como dirían Michel Foucault y otros críticos postestructuralistas, las personas en sus palabras privadas y reflexiones personales a menudo reflejan, generalmente inconscientemente, diversas costumbres públicas o normas sociales. Si bien estas reflexiones personales se convierten en fuentes útiles para comprender estas perspectivas sociológicas más amplias, son los filtros personales los que revelan el carácter interno de quien crea los registros. Aquí tenemos la psicología de los archivos más que su transaccionalidad. (127)

Las intenciones autobiográficas que recorren a los fondos personales los vuelven pasibles de operaciones - conscientes o inconscientes- de destrucción, soslayamiento y puesta en relieve de ciertos tramos de una vida, ya sea por la persona que produce el fondo, por sus descendientes, y/o por los discípulos. En los fondos institucionales, especialmente en aquellos pertenecientes a los Estados regidos por democracias formales, se espera que las operaciones de ordenamiento $\mathrm{y}$ descarte de documentos respondan a procedimientos estandarizados y los silencios a falencias institucionales, pero no a decisiones de quienes los preservan. Esto se complejiza con los numerosos regímenes dictatoriales que decidieron "limpiar" los archivos del Estado y de sus Fuerzas Armadas para no dejar testimonios de la represión y otras prácticas ilegales. Y en esto los fondos institucionales se asemejan a los personales, pues las decisiones son constitutivas y es un desafío para archivistas e historiadores precisar los orígenes del ordenamiento e identificar los silencios así como las huellas de resistencia, o incluso de enfrentamiento al control institucional. Ante ese desafío, el análisis del discurso, la antropología, la historia, la semiótica y la psicología, entre otras disciplinas humanísticas, se presentan como herramientas fundamentales. 
La reflexión y valoración de los fondos personales no solo se ha registrado en la archivística, sino también en la historia. En las últimas dos décadas del siglo XX, el interés historiográfico por las grandes personalidades y por las abarcadoras estructuras sociales y políticas se ha desplazado a la "gente común" y a los "hombres infames", a la prosopografía, a las redes de sociabilidad y a la contracultura cuestionadora de aquellas estructuras. Carlo Ginzburg, Michel Foucault y Arlette Farge, entre otros, ofrecieron indiscutidas muestras de que los fondos institucionales pueden ser interrogados de modo tal que permitan precisas reconstrucciones y análisis de quienes no solo no participaron de la cultura letrada sino que además estuvieron socialmente marginados. Y la historia de las mujeres viene ofreciendo más muestras de la riqueza que portan ese tipo de fondos cuando se los recorre a contrapelo. ${ }^{2}$ De todos modos, la "historia desde abajo", la historia cultural y la historia intelectual, sobre todo, han insistido en que, además de los fondos institucionales, se requiere de los generados por personas, y especialmente de las correspondencias. Es que durante todo el siglo XX las cartas fueron un masivo y frecuente medio para intercambiar ideas, establecer y mantener amistades político-intelectuales, organizar redes y construir una multifacética cultura de escala internacional. Y a través de la correspondencia la investigación histórica no solo accede a esa cultura, sino también a un registro intimista y a la posibilidad de su contraste con el registro público, cuestiones que de otro modo parecían irrecuperables (Petrucci). ${ }^{3}$

Esta renovación historiográfica ha tramado algunos cruces con la archivística, pero estos, sin duda, podrían intensificarse con prometedores resultados en ambas disciplinas. En efecto, si las investigaciones históricas basadas en fondos personales asumieran con más convicción el principio de la archivística sobre los documentos como piezas de un conjunto con una lógica a desentrañar, la sistemática interrogación sobre la relación de un documento con el conjunto en el que se inscribe permitiría una aproximación histórica más rica. Por su parte, la archivística podría mejorar su aproximación a la lógica de los fondos si desarrollara una sensibilidad histórica mayor, que colocara en un lugar

Para el caso europeo se destaca la obra monumental de Georges Duby y Michelle Perrot (2000).

3 El dossier publicado hace veinte años por la revista Estudos Históricos sigue ofreciendo una síntesis fundamental de los debates sobre los archivos personales, sus usos historiográficos y las tensiones con la archivística. Allí se recogen las intervenciones que, en el marco del Seminário Internacional sobre Arquivos Pessoais, que organizó en noviembre de 1997 el Centro de Pesquisa e Documentação de História Contemporânea do Brasil (CPDOC), realizaron referentes de la historiografía francesa (Philipe Artieres, Christophe Prochasson), uno de los máximos representantes de la corriente canadiense de la "archivística posmoderna" (Terry Cook) y especialistas del Brasil (http://bibliotecadigital.fgv.br/ojs/index.php/reh/issue/view/287). 
central la reposición de los itinerarios político-culturales y los vínculos subjetivos $\mathrm{y}$ afectivos de quienes generaron los fondos personales o estuvieron involucrados en su ordenamiento y preservación. En palabras de Lucas Domínguez Rubio, "los principios de la archivística que recomiendan mantener la procedencia y el respeto al orden original resultan también principios gnoseológicos útiles para la historiografía, en la medida en que ésta requiere poder dimensionar un documento en el acervo en que se lo conservó al momento de utilizarlo dentro del corpus de una investigación" (55).

Si bien se debe seguir avanzando, subrayemos que los fondos personales se han vuelto un nuevo pilar de la producción histórica y de la labor archivística, al tiempo que citas como aquella sugieren que también desde la historia se han registrado significativas reflexiones. ${ }^{4}$

\section{LOS FONDOS DOCUMENTALES DE LA REFORMA UNIVERSITARIA}

La primera generación de reformistas desplegó una decidida política de memoria sobre el movimiento estudiantil que estaba construyendo. Y ello no solo se advierte en los numerosos artículos y ensayos que esa generación publicó a lo largo de su vida, sino también en la dedicación con la que conservó tanto los ejemplares de las revistas que editaba o recibía como los manuscritos que redactaba, los afiches y volantes que ponía a circular, la correspondencia que mantenía y los telegramas intercambiados entre las federaciones universitarias. Lamentablemente, las generaciones que en los años posteriores quedaron a cargo de esos materiales no siempre pusieron la misma dedicación en la preservación de la memoria de la Reforma y muchos de esos fondos personales hoy están perdidos, dispersos o arrumbados en condiciones que no aseguran su pervivencia ni su posibilidad de consulta. A ello se suma otra situación lamentable: la estrecha comprensión del patrimonio cultural de los investigadores que, a pesar de trabajar en instituciones estatales vinculadas a archivos, asumen la custodia de fondos de figuras relevantes de la Reforma de modo exclusivo, esto es, no entregan esa documentación -y ni siquiera una copia- a los archivos de acceso público, al tiempo que les niegan el acceso a otros investigadores. Una situación que al presente se registra, al menos, en los fondos de Deodoro Roca (18901942), Juan Probst (1892-1973) y Carlos Astrada (1894-1970).

4 Entre esas reflexiones se encuentran Prochasson, Artières y Kalifa, Tarcus ("Los archivos del movimiento") y Caimari. 
Aquella temprana voluntad de preservar la memoria de la Reforma logró un importante resultado en diciembre de 1926, cuando el Centro de Estudiantes de Medicina de la Universidad de Buenos Aires financió la publicación del primero de los seis tomos de La Reforma Universitaria. Ese no fue el primer libro que relató, desde la perspectiva de los reformistas, los acontecimientos que sucedieron a la revuelta cordobesa de junio de 1918 y que reprodujo algunos documentos, pues en 1922 el líder platense Julio V. González (1899-1955) editó La revolución universitaria. Pero la compilación documental de 1926-27 no solo fue más amplia, sino que además circuló entre los estudiantes de América Latina como testimonio de los sucesos, como material de formación política y como definición de una genealogía. Pero también esa compilación recortó un corpus documental que contados historiadores procuraron ampliar. ${ }^{5}$

5 Los títulos de cada tomo son los siguientes: I. Juicio de hombres de la nueva generación acerca de su significado y alcances (1918-1926); II. Documentos relativos al movimiento estudiantil en las universidades de Córdoba y Buenos Aires (1918); III. El primer Congreso Nacional de Estudiantes Universitarios, Córdoba, 1918; IV. Documentos relativos al movimiento estudiantil en La Plata (1919-1920); V. Documentos complementarios que se refieren a la acción directamente social del movimiento estudiantil argentino (1918-1921), con un apéndice relativo a la campaña contra la limitación del ingreso a las universidades (1926); VI. Documentos relativos a la propagación del movimiento en América Latina (1918-1927). 
Imagen 1: Portada de La Reforma Universitaria.

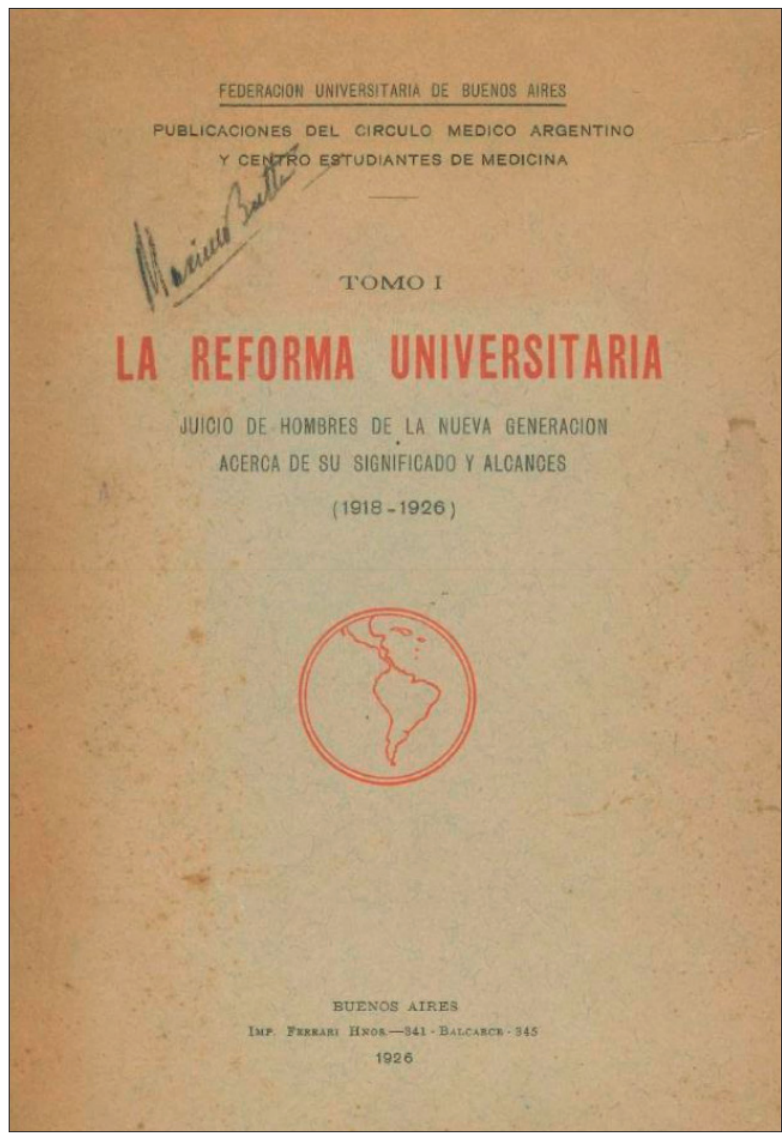

Fuente: Del Mazo, Gabriel. La Reforma Universitaria. Tomo 1. Centro de Estudiantes de Medicina de la Universidad de Buenos Aires, Federación Universitaria Argentina, 1926. (Donación León Ferrari, CeDInCI).

La organización de los documentos fue temática y estuvo al cuidado de Gabriel del Mazo (1898-1969), un joven ingeniero porteño que había sido líder inicial de la Reforma y que vincularía su itinerario político-intelectual posterior al reformismo y a la fracción yrigoyenista de la Unión Cívica Radical. Del Mazo reprodujo manifiestos, declaraciones, actas, ensayos y notas breves que recuperaban tanto las diversas iniciativas desplegadas entre 1918 y 1926 por los reformistas como las distintas fracciones que se disputaron la definición del 
movimiento. Pero ese amplio mapeo no le impedía dejar en claro la definición social que impulsaba. El primer tomo, el segundo y el sexto se abrían con un mismo documento, "La juventud de Córdoba a los hombres libres de Sud América", redactado en junio de 1918 por Deodoro Roca y puesto a circular entonces, y en la compilación, con la firma de la Junta directiva de la Federación Universitaria de Córdoba. Contra los manifiestos propuestos por la fracción nacionalista y antisocialista, del Mazo y quienes alentaban la vinculación del movimiento con las preocupaciones sociales y las izquierdas lograban que aquel documento se transformara en el hoy célebre "Manifiesto liminar" de la Reforma. Ello implicaba que las revueltas de 1918 -y no la reflexión que, según la fracción nacionalista, había llegado en 1919- inauguraron un movimiento estudiantil de carácter antioligárquico. Este tendría escasos antecedentes estudiantiles y su línea más prometedora en un latinoamericanismo preocupado no solo por la democratización de las universidades, sino también por la denuncia del imperialismo estadounidense y de las desigualdades sociales.

En 1941, la edición de 1927 resultaba de difícil acceso para las nuevas generaciones de reformistas y del Mazo preparaba una nueva compilación con el mismo título, pero en solo tres tomos que volvían a circular entre los reformistas latinoamericanos. Allí se incorporaban documentos difundidos entre 1927 y 1940, pero también se omitían varios de los editados anteriormente y se proponía una nueva organización temática. ${ }^{6}$ Sin duda, en esas décadas de nulas políticas estatales de memoria sobre las izquierdas y los movimientos sociales, las compilaciones de del Mazo aseguraron que al menos se conservaran las reproducciones de numerosos documentos reformistas cuyos originales, en muchos casos, terminaron en tachos de basura o permanecen en manos de coleccionistas particulares. Pero además del Mazo tomaba decisiones archivísticas e historiográficas. Para la edición de 1941 seleccionaba un mayor número de documentos que registraban los lazos de la Reforma con proyectos democráticos distantes de las izquierdas radicalizadas, al tiempo que su prólogo, anotaciones a pie de página y ordenamiento enfatizaban esos lazos. Y las características del campo historiográfico argentino -fundamentalmente,

Del Mazo era profesor en la Facultad de Ingeniería de la Universidad Nacional de La Plata y dos años después sería vicepresidente de esa Universidad bajo la breve presidencia del socialista Alfredo Palacios. Los títulos de cada tomo fueron: I. El Movimiento Argentino; II. Propagación americana; III. Ensayos Críticos. La comparación de estos títulos con los de la edición de 1927 pone de manifiesto que del Mazo ya no consideraba tan importante la vinculación de la Reforma con el movimiento obrero, registrada en el tomo quinto sobre la "acción social". Y el mismo del Mazo sugiere esa pérdida de importancia cuando en una cita aclara que sobre la acción social el lector debe remitirse a ese tomo quinto, que entonces era de muy difícil acceso. 
la escasa financiación para la investigación y el difícil acceso a fondos documentales- harían que esas decisiones, lejos de abrir la discusión histórica y política, ejercieran un importante condicionamiento en los balances sobre el movimiento reformista.

Del Mazo había extraído de las revistas, periódicos y ensayos de época los materiales que consideraba más significativos. Y si bien mencionaba las fuentes al final de cada tomo, las compilaciones y análisis posteriores -salvo contadas excepciones- recurrieron únicamente a los materiales seleccionados por del Mazo. En efecto, la compilación de fuentes que publicaba en 1978 la Biblioteca de Ayacucho, entonces una de las editoriales de mayor circulación en el continente, aclaraba que los documentos habían sido extraídos de la edición de del Mazo de 1941. Es decir, si Dardo Cúneo (1914-2011), el prologuista y responsable de la selección de fuentes, no dudaba de los rasgos democratizadores y distantes de la radicalidad política que, según mostraban los documentos, había tenido la Reforma en su despliegue argentino, no era porque había encontrado nueva documentación que confirmara esos rasgos, sino porque había analizado y reorganizado la rescatada por del Mazo. ${ }^{7}$ Por su parte, el mismo año 1978 otra importante editorial latinoamericana, Siglo XXI, editaba su compilación de documentos sobre la Reforma. Aunque no se lo explicite, la mayoría proviene de la misma edición de 1941. En Estudiantes y política en América latina (1918-1938). El proceso de la Reforma Universitaria, Juan Carlos Portantiero (1934-2007), el responsable del extenso y agudo ensayo introductorio y de la selección, se decepcionaba del moderatismo de los reformistas argentinos, pero no emprendía una búsqueda de documentos que le permitiera registrar y evaluar la presencia de corrientes radicalizadas. ${ }^{8}$

Entre los ensayos preparados por líderes reformistas, Lineas y trayectorias de la Reforma Universitaria, publicado en 1935 por el anarquista rosarino Juan Lazarte (1891-1963), probablemente sea el que más se preocupó por discutir la apuesta historiográfica y las limitaciones archivísticas que acompañaban a la identificación de la Reforma con el moderatismo político en el que insistía del Argentina. Su documentación no registra la elaboración del libro mencionado pero sí la importante labor editorial de Cúneo en la Biblioteca de Ayacucho.

8 Agotado hace décadas, este libro tuvo su segunda edición en 2018, cuando Eduardo Rinesi y Adriana Puigróss prepararon una edición en dos tomos y dos prólogos que aparecieron en la editorial universitaria EUFyL. Allí se incorporó el capítulo "Estudiantes y populismo" que había aparecido en la versión italiana, editada por Portantiero siete años antes que la mexicana (Portantiero, Studenti e rivoluzione nell'América Latina, Il Sagiarore, Milán, 1971). La primera traducción y publicación en español de ese capítulo se realizó recién en 2012 (Bustelo y Celentano). 
Mazo y al que se sumaba, entre otras, la línea historiográfica abierta, en afinidad con el Partido Socialista, por Julio V. González.

En la última década algunos/as investigadores/as realizamos nuevos rastreos biblio-hemerográficos que ampliaron considerablemente el corpus documental sobre la Reforma y desde ese nuevo corpus ofrecimos reflexiones sobre las olvidadas iniciativas e ideas que disputaron el moderatismo (Pita González; Bustelo y Domínguez Rubio; Tarcus, “Di tu palabra”). ${ }^{9}$ Pero todo ello aún no ha redundado en una edición de documentos reformistas que provenga de un nuevo y minucioso trabajo de selección de los materiales producidos por estudiantes durante las primeras décadas del siglo XX. Una tarea que, sin duda, se encuentra allanada por la política de memoria que viene desarrollando el CeDInCI.

En efecto, su biblioteca ha reunido, además de los libros que analizan la Reforma, una de las colecciones más completas de ensayos y folletos provenientes de reformistas argentinos y latinoamericanos. A los escritos de combate de del Mazo y González se suman los de los "maestros de la juventud” José Ingenieros, Alejandro Korn y Alfredo Palacios y de los líderes estudiantiles Deodoro Roca, Saúl Taborda, Carlos Sánchez Viamonte, Gregorio Bermann, Aníbal Ponce y Héctor Agosti. Entre los escritos de los reformistas latinoamericanos se conservan los del colombiano Germán Arciniegas, el guatemalteco Juan José Arévalo, el boliviano José Antonio Arze, el cubano Antonio Mella y los peruanos Raúl Haya de la Torre, Manuel Seoane y Luis Alberto Sánchez. El CeDInCI ha constituido, a su vez, una de las bibliotecas más completas de las obras de y sobre José Carlos Mariátegui (1894-1930), el intelectual y militante marxista peruano que hizo una importante apuesta por el movimiento de la Reforma y del que se conserva su fondo en Lima y en un cuidado repositorio digital (https://www.mariategui. org).

En cuanto a la hemeroteca del CeDInCI, su pilar inicial fue la adquisición en 1997 de la extraordinaria colección de revistas y periódicos del activista gremial y militante político José Paniale y se complementó en 2005 con la compra de parte de la colección de Gabriel del Mazo a una librería de la ciudad de Buenos Aires. Además, se enriqueció con la incorporación por donación de los fondos de Héctor Raurich, José Ingenieros, Liborio Justo y Florentino y del presente artículo han curado la muestra "Las revistas estudiantiles y la Reforma Universitaria (1908-1928)", expuesta en el hall del CeDInCI y en el de la Biblioteca Central de la UNSAM y cuya versión digital puede consultarse en: http://exhibiciones.cedinci.org/exhibits/show/reforma universitaria. 
Horacio Sanguinetti. ${ }^{10}$ Los números faltantes en las colecciones se completaron a través de una búsqueda sistemática en remates, librerías y archivos privados.

Imagen 2: Ejemplar de una revista perteneciente al Fondo Sanguinetti, CeDInCI, en la que se observa la inscripción del envío postal.

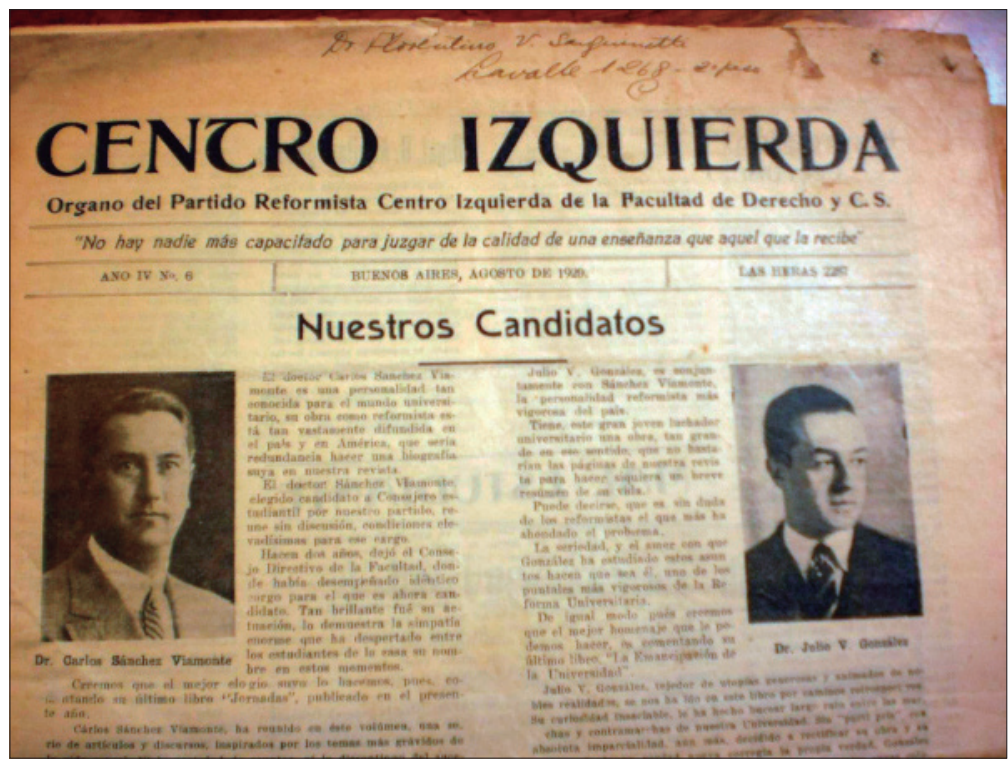

Fuente: Fondo Sanguinetti, CeDInCI.

Gracias a la conjunción de esas perseverantes políticas de búsqueda, de compra y de recepción se ha conseguido recuperar una extensa y diversa colección de revistas estudiantiles, gacetas y boletines ligados a la Reforma. Además, AméricaLee, el portal digital de revistas latinoamericanas del CeDInCI (http://americalee.cedinci.org), ofrece a la consulta en línea -junto a su índice

Específicamente, la colección de la revista Inicial (1923-1927) fue conservada en el Fondo Liborio Justo. Algunos números de Centro Izquierda. Órgano del Partido Reformista de Centro Izquierda (1926-1929) y su sucesor Izquierda (1931-1935) llegaron al CeDInCI dentro del legado de Raurich y otros en el Fondo Sanguinetti. Este Fondo junto al de Ingenieros fueron fundamentales para contar con las colecciones del Boletín de la Federación Universitaria de Buenos Aires (19171918), su equivalente nacional y las gacetas de otras federaciones universitarias argentinas. La colección de las platenses Valoraciones (1923-1928) y Sagitario (1923-1927) provienen del Fondo José Paniale mientras que el Fondo de la militante gremial Margarita Paniale aportó numerosas revistas político-culturales vinculadas al magisterio. 
y un estudio preliminar- varias revistas que, a pesar de que fueron centrales en la primera expansión de la Reforma, continuaban siendo de muy difícil acceso. Entre ellas, los Cuadernos del Colegio Novecentista (Buenos Aires, 1917-1919), Clarín. Órgano del Ateneo Universitario de Buenos Aires (Buenos Aires, 19191920), Bases. Tribuna de la juventud (Buenos Aires, 1919-1920), Insurrexit. Revista universitaria (Buenos Aires, 1920-1921), Inicial. Revista de la nueva generación (Buenos Aires, 1923-1927), La Reforma. Órgano del Comité Pro Afianzamiento de la Reforma Educacional (La Plata, 1920), Mente. Publicación de crítica social (Córdoba, 1920), Boletín de la Federación Universitaria Argentina (Buenos Aires, 1920-1923), Tribuna Universitaria (Rosario, 19211922), Alborada. Órgano del Ateneo estudiantil (La Plata, 1920-1921).

En definitiva, la hemeroteca y el portal digital reúnen la mayoría de las publicaciones periódicas de las que del Mazo extrajo los documentos de sus compilaciones. Y, como sugerimos, para una investigación que se proponga recuperar la riqueza política y cultural de la Reforma es imprescindible un análisis de esos documentos que, siguiendo los criterios archivísticos del principio de procedencia y de orden original, atienda al contexto original de circulación, recupere otros materiales junto a los que circularon las intervenciones e ideas de los documentos seleccionados por del Mazo y reconstruya las vías materiales que hicieron posible y condicionaron esa circulación. Cuestiones que, sin duda, también conciernen a las investigaciones sobre otros movimientos políticoculturales.

En tercer lugar, el CeDInCI alberga varios fondos personales que son decisivos para una renovación historiográfica que se ocupe no solo de los reformistas destacados (esto es, de los jóvenes que pronunciaron discursos, redactaron ensayos y dirigieron federaciones y revistas estudiantiles), sino también de las llamadas "figuras menores", es decir, de quienes organizaron los mitines en los que disertaron los líderes, leyeron y distribuyeron las revistas estudiantiles y expandieron el movimiento en casas de estudio remotas y pequeñas.

\section{LOS PAPELES DE LOS ANIMADORES DE LA REFORMA UNIVERSITARIA COMO "FONDOS PERSONALES"}

Como mencionamos, los estudiantes que buscaron convertir las revueltas estudiantiles cordobesas de 1918 en un movimiento estudiantil de escala nacional fueron los más comprometidos albaceas de la memoria de la Reforma. Un índice de ese compromiso lo ofrece uno de los documentos conservados en el Museo 
Casa de la Reforma, dependiente de la Universidad Nacional de Córdoba. A comienzos de 1920, el joven cordobés Enrique Barros (1893-1961) le escribía desde Rosario al estudiante porteño Gregorio Bermann (1894-1972) para confirmarle que había logrado contactarse con los jóvenes que allí apostaban a la misma definición revolucionaria de la Reforma. Pero antes le avisaba: "Querido Bermann: Hoy debes recibir los cajones repletos de documentos relativos a la Revolución Universitaria. Me ha absorbido su preparación largo tiempo sin que me bastara para ordenarlos debidamente. Los pongo en tus manos con plena confianza. Utilízalos como convenga y después los volverás a mi poder".

Una atenta reconstrucción de las iniciativas reformistas sugiere que Bermann le había solicitado esos documentos para preparar la conferencia que unas semanas después daría en Montevideo ante el Centro Ariel, que lideraba el estudiante de derecho y futuro líder de la izquierda nacional uruguaya Carlos Quijano (1900-1984). Hoy conocemos la larga conferencia de Bermann sobre "La revolución estudiantil argentina" porque Ariel, la revista del centro montevideano, en sus números 12 y 13/14 (correspondientes a agosto y septiembre/octubre de 1920) la difundió entre los estudiantes de entonces y porque la actual revalorización archivística e historiográfica de las revistas culturales se ha traducido en la puesta en acceso público de una colección parcial de Ariel (http://anaforas.fic.edu.uy/jspui/handle/123456789/13). ${ }^{11}$

Pero esos "cajones repletos de documentos relativos a la Revolución Universitaria" parecen haber ejercido otro rol significativo en la memoria de la Reforma. Barros murió en marzo de 1961 y las generaciones siguientes, aparentemente, no salvaron esos documentos de la dispersión y desaparición. ${ }^{12}$ La larga amistad político-intelectual que establecieron Barros y Bermann nos hace suponer que este cumplió con el pedido de devolver los documentos luego de "utilizarlos como convenga". Por su parte, del Mazo recuerda en sus memorias que también mantuvo una entrañable amistad con Barros. Y no es insensato suponer que el cordobés le haya mandado a del Mazo los mismos cajones -tal vez sin haber encontrado aún el tiempo necesario "para ordenarlos debidamente"- para que seleccionara los que debían reproducirse en esos seis tomos de 1926-27 que hoy nos permiten contar con un conjunto importante de manifiestos, declaraciones y artículos que circularon en los inicios de la Reforma.

11 “Anáforas. Publicaciones periódicas del Uruguay" viene realizando una muy valiosa tarea de conservación y difusión de publicaciones periódicas del acervo cultural nacional de los siglos XIX y XX. Sus inicios se remontan a un proyecto iniciado en 2004 por Lisa Block de Behar.

12 El Museo Casa de la Reforma de la UNC solo conserva los documentos generados por Barros durante las últimas décadas de su vida, cuando tuvo como secretaria a Susana Tampieri. 
Sobre el envío solo podemos hacer conjeturas porque, además de conservarse una pequeña parte de la documentación reunida por Barros, el voluminoso fondo que del Mazo generó a lo largo de su vida fue desguazado y rematado entre coleccionistas privados en las dos últimas décadas. La excepción a la dispersión y preservación en manos de privados es un conjunto de folletos, volantes mecanografiados, revistas y recortes de artículos que el CeDInCI compró junto a las revistas mencionadas y ofrece desde entonces a la consulta. Pero no se trata de documentación sobre los inicios de la Reforma, sino de valiosos documentos relativos a "la laica o la libre", esto es, al álgido debate que se produjo entre 1956-1970 en el parlamento y el movimiento estudiantil argentinos ante la legalización de la educación formal religiosa.

Un destino mejor al sufrido por el fondo de Barros y el de del Mazo lo tuvieron los de otros dos destacados líderes reformistas, Bermann y Florentino Sanguinetti (1893-1975). En 2009 Sylvia Bermann donó unos 10.000 documentos reunidos por su padre Gregorio al Centro de Estudios Avanzados de la Universidad Nacional de Córdoba. En los últimos años ese Fondo ha sido catalogado y puede consultarse en ese Centro; además, una parte importante está digitalizada y es de acceso público (https://archivogregoriobermann.sociales.unc.edu.ar). Allí se conservan numerosas cartas recibidas por Bermann mientras que una decena de piezas -entre las que se encuentra la citada arriba- es custodiada por el Museo Casa de la Reforma.

En cuanto al fondo reunido por Sanguinetti, desgraciadamente se ha disgregado en tres espacios. Una gran parte -a la que su hijo Horacio, antes de donarlo, le incorporó documentación de las décadas del setenta y ochentaes custodiada por el CeDInCI (http://archivos.cedinci.org/index.php/fondohoracio-y-florentino-sanguinetti). Estas catorce cajas se completan con un conjunto pequeño de documentación donado al Instituto de Investigaciones Jurídicas y Sociales "Ambrosio L. Gioja", dependiente de la Universidad de Buenos Aires, y otro conjunto que custodia el Museo Casa de la Reforma.

La documentación reunida por Bermann permite precisar que fue Barros quien insistió para que aquel y su primera esposa, la feminista socialista Leonilda Barrancos (1890-1954), se mudaran a Córdoba y se incorporaran a esa red reformista, al tiempo que registra la preocupación de Bermann por una medicina social y su compromiso con el antifascismo y el comunismo. El Fondo Sanguinetti del CeDInCI, por su parte, ofrece la reconstrucción de otra fracción del reformismo argentino. Allí se conservan numerosos documentos provenientes de la militancia estudiantil que Florentino inició en la década del diez, cuando estudiaba en la Facultad de Derecho de la Universidad de Buenos Aires, y que continuó una vez graduado. Los volantes, manuscritos, mecanografiados, 
programas de cursos, recortes, cartas, afiches y revistas que componen ese Fondo permiten una minuciosa reconstrucción de la decidida militancia que, desde 1918, libraron Sanguinetti y un grupo de jóvenes graduados y estudiantes para instalar en esa Facultad las medidas democratizadoras y antioligárquicas asociadas a la Reforma (Bustelo).

Además de conservar documentación sobre la trama de ideas, iniciativas y personas que logró que entre 1921 y 1923, desde el decanato de Mario Sáenz, la Facultad se acercara al movimiento obrero y se preocupara por impulsar un derecho de carácter social, el Fondo refleja las mutaciones de ese reformismo en las décadas siguientes. Y su documentación sobre el antifascismo, el enfrentamiento estudiantil al peronismo y la construcción de una Unión Cívica Radical Intransigente contienen interesantes referencias y vinculaciones con los documentos conservados por Bermann. Entre las más de cien cartas fechadas entre 1920 y 1960 que Sanguinetti reunió, se encuentra la copia mecanografiada de la primera carilla de una, fechada el 7 de marzo de 1932, que permite recuperar la conciliación entre socialismo y Reforma que Bermann y Sanguinetti junto a otros reformistas venían realizando, pero también registra el distanciamiento que entonces se iniciaba.

En 1931 Deodoro Roca y Gregorio Bermann llevaban su prestigio reformista a una disputa electoral que sabían de antemano derrotada. En el marco de la Alianza del Partido Socialista con el Partido Demócrata Progresista se erigían en candidatos a intendente de la ciudad de Córdoba y a gobernador de la provincia de Córdoba, respectivamente. De la correspondencia que entonces mantenían Bermann y Sanguinetti el Fondo del último conserva tres cartas. En la mencionada carilla del 7 de marzo de 1932, luego de agradecer la información sobre el estado de salud de un tercer líder reformista, Carlos Sánchez Viamonte (1892-1972), Sanguinetti intentaba convencer a Bermann de que retirara su renuncia del Partido Socialista porque "es hombre necesario al movimiento de ideas que polariza el partido y debe prestarle la eficacia característica de su dinamismo. [...] Sus opiniones en materia universitaria conocidas por La Vanguardia [el periódico oficial del Partido Socialista] denuncian como siempre, que Ud., es hombre para la muchedumbre, tanto como para la cátedra, y debe mantenerse en esa actividad indivisible". Bermann no se dejaba convencer de la vuelta al partido. Pero si no renunciaba a mantener unidas su interpelación a la muchedumbre y su actividad universitaria, era porque en la década del treinta se transformaba en "compañero de ruta" del Partido Comunista, mientras que Sánchez Viamonte optaba por el Partido Socialista y Roca simpatizaba con el trotskismo.

El voluminoso epistolario de Sanguinetti, además de ser una vía fundamental para precisar esas apuestas y distanciamientos entre las figuras consagradas de la Reforma, permite registrar la participación de algunas 
figuras en periodos breves o desde posiciones relegadas. $\mathrm{Y}$ así descubre una de las amplias redes que estuvieron involucradas en la democratización de las universidades latinoamericanas y en la politización de los estudiantes.

Otro fondo personal custodiado por el CeDInCI, el que reunió Néstor Grancelli Cha (1920-2014) en 2012, ofrece más documentación relativa a la prédica antifascista del reformismo argentino durante la Segunda Guerra Mundial y a la oposición a la presidencia de Perón (http://archivos.cedinci.org/ index.php/nestor-grancelli-cha-fondo). ${ }^{13}$ El Fondo se compone de cuatro cajas de recortes, cartas, volantes y fotografías vinculadas a las iniciativas emprendidas en la década del cuarenta por la Federación de Estudiantes del Litoral (FUL) y la Federación Universitaria Argentina (FUA). La documentación reunida confirma que Grancelli Cha ingresó en 1939 a la Facultad de Ciencias Económicas, Comerciales y Políticas de la Universidad Nacional del Litoral, ubicada en la ciudad de Santa $\mathrm{Fe}$, y que en los años siguientes realizó una ascendente carrera de cargos universitarios y que, por un breve periodo, se incorporó, en vinculación con del Mazo, a la Unión Cívica Radical Intransigente. Además, se registra su paso inicial por la secretaría de la FUL, su acción como delegado en el Consejo Superior de esa Universidad, su vicepresidencia en el Congreso Nacional de Universitarios, su presidencia en la FUA y los cargos de gestión que ocupó durante el gobierno de Arturo Frondizi (1958-1962), primero como secretario de Relaciones Económico-Sociales y luego como agregado económico en la embajada argentina en México.

Otra parte de la memoria del reformismo santafesino y nacional es documentada por el pequeño Fondo personal de Oscar Juanto (1904-1964), que el CeDInCI custodia desde mediados de 2018, luego de que fuera donado por su hija Amelia Juanto y su nieta Marcela Nicastro (http://archivos.cedinci. org/index.php/oscar-juanto-fondo). Juanto conservó documentos relativos a su militancia reformista de mediados de la década del veinte, cuando era estudiante de odontología en Rosario. Allí se encuentran varias fotografías y algunos números de la revista del Centro de Estudiantes que estaban perdidos. Además se registra el concurso que ganó en la cátedra de Odontología legal, social y economía dental y su participación en el gremialismo médico de la provincia de Santa Fe.

13 En 2011, Grancelli Cha publicó su autobiografía, y por recomendación de Horacio Sanguinetti eligió al CeDInCI para custodiar los documentos sobre la universidad que había reunido hasta la década del sesenta. Además de entregar la documentación en un minucioso orden, Grancelli Cha valoraba de tal modo el legado de los fondos personales, que con 93 años colaboró en la descripción de muchos de los documentos que donó. 
A diferencia de los otros fondos personales que mencionamos, este responde a una figura que tuvo una militancia poco destacada en el movimiento reformista y que actuó en una carrera pequeña y poco politizada como odontología. Ello convierte a las dos cajas de documentos que componen el Fondo Juanto en una vía privilegiada no solo para conocer los modos en que se expandió la Reforma en ese tipo de carreras, sino también para confirmar que las inquietudes políticas que despertaba el reformismo marcaron el itinerario profesional posterior, tanto de los líderes como de las "figuras menores". Más precisamente, Juanto puso especial dedicación en conservar los documentos relativos a su concurso en la cátedra de Odontología legal, social, y economía dental. Y el dato de que haya procurado y ganado una cátedra en la que podía desarrollar conjuntamente su profesión y la preocupación social adquiere otra significatividad cuando atendemos a que los fondos personales de otros reformistas confirman y precisan un similar empeño en la búsqueda y obtención de cátedras en las que la profesión se vincula a los problemas sociales. En efecto, en el mencionado epistolario de Barros a Bermann aquel le aseguraba que los reformistas cordobeses lo consideraban imprescindible en Medicina legal y toxicología, esto es, la cátedra de medicina que era equivalente a la de odontología que ocuparía Juanto. Bermann ganaría el concurso para acceder a esa cátedra a fines de 1921 y su impronta izquierdista decidiría que en los años siguientes fuera exonerado por las gestiones antirreformistas y reincorporado por la presión reformista. 
Imagen 3: Primera página del Curriculum Vitae de Oscar Juanto para el Concurso de la cátedra de Odontología Legal, Social y Economía Dental de la Escuela de Odontología de la Universidad Nacional del Litoral en 1951. Fondo Oscar Juanto. CeDInCI.

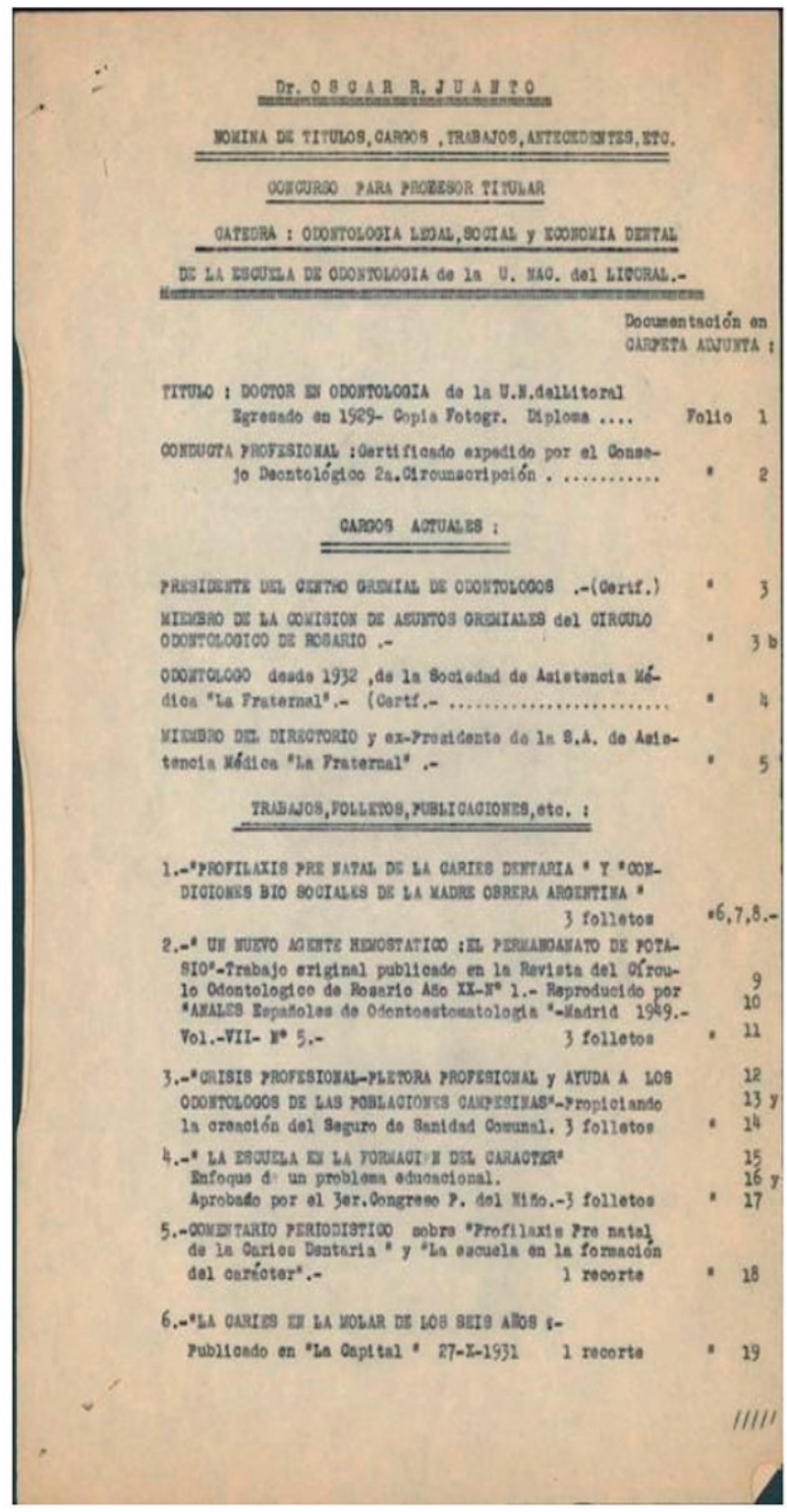

Fuente: Fondo Oscar Juanto. CeDInCI. 
En cuanto a la carrera de derecho, varios documentos del Fondo Sanguinetti muestran que desde 1919 el grupo de la Facultad de Derecho de la Universidad de Buenos Aires en el que aquel actuaba organizó no solo cursos de extensión para que los obreros conocieran la legislación que los amparaba, sino también cursos libres para que los estudiantes comprendieran que el código romano que venían aprendiendo no podía resolver los problemas legales de las sociedades contemporáneas. Según insistía el abogado y "maestro de la juventud" Alfredo Palacios (1880-1965), la sociología y la medicina social debían encargarse del estudio de las sociedades y ofrecer sus resultados para la elaboración de un nuevo derecho y sobre todo - dada la injusta organización social vigente- de una legislación obrera. Agreguemos que si la reconstrucción del itinerario políticointelectual de Sánchez Viamonte descubre que este líder reformista fue el que sucedió a Palacios en la insistencia de un derecho social similar, la atención a las biografías reformistas confirma que la cátedra de Medicina social de la carrera de medicina de Buenos Aires también fue ocupada por un líder reformista vinculado al socialismo, José Belbey (1894-1960). ${ }^{14}$

La convergencia entre profesión y preocupación social también se advierte en las más de veinte cajas de documentación que conforman el Fondo personal de Eugenio Zanetti (1910-1971), donado al CeDInCI por su nieta Candela Casas en 2017 (http://archivos.cedinci.org/index.php/eugenio-zanetti-fondo). Si, en su época de estudiante de derecho en Córdoba, Zanetti se vinculó al reformismo y estableció relación con Bermann, ya recibido esa militancia estudiantil lo convirtió en fundador y director del Colegio Libre de Cultura Popular de Córdoba y seguramente motivó su interés por la enseñanza, la sociología, y las bibliotecas populares.

14 Una similar sobredeterminación profesional se descubre en el reformista y médico higienista Noé H. Sbarra (1907-1974), cuyo itinerario en la ciudad de La Plata reconstruyeron y analizaron Adrián Celentano, Néstor Arrúa y María Josefina Lamaisón (Celentano 2019). 
Imagen 4: Fragmento del manifiesto de la Unión Libre Universitaria de Córdoba. 1932.

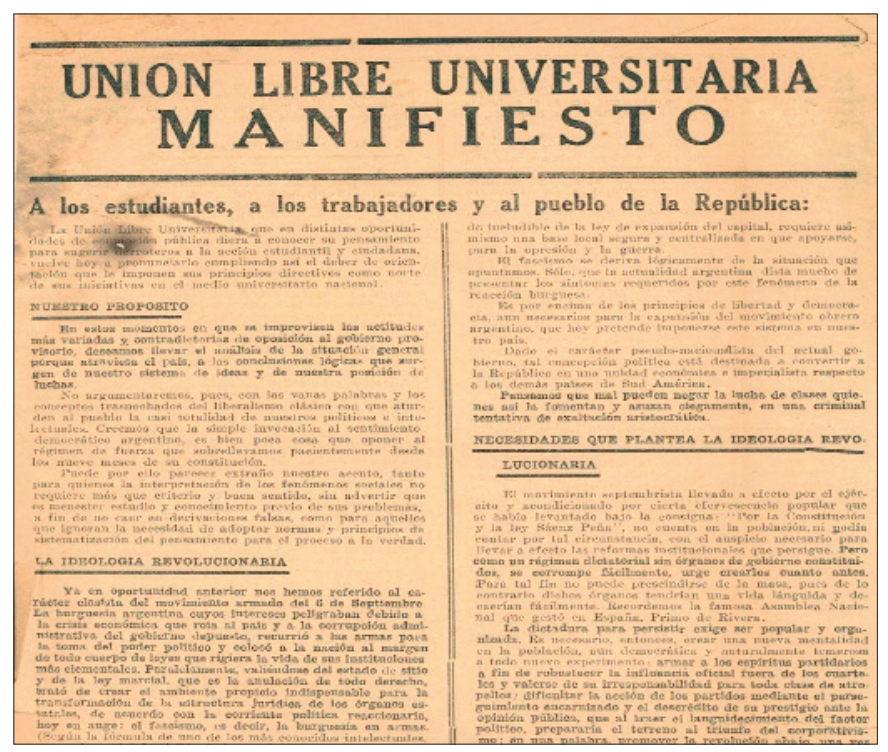

Fuente: Fondo Juan E. Zanetti. CeDInCI.

Al igual que en el Fondo Sanguinetti, la gran cantidad de cartas de aquel Fondo son fundamentales para reconstruir la extendida red de militantes y funcionarios que entre la década del cuarenta y la del sesenta animaron una de las fracciones reformistas de Córdoba. Específicamente, mientras que un grupo de documentos registra los proyectos colectivos ligados a la pedagogía y la sociología argentina, otro refiere al breve paso de Zanetti como decano de la Universidad Nacional del Litoral, a su presidencia en el Consejo de Enseñanza Secundaria Normal y Especial (1958-1959) y a su participación en la Mesa Directiva del Consejo Federal de Enseñanza Técnica (1958-1959). Un tercer grupo de documentos se vincula a la promoción conjunta de las bibliotecas populares, a la presidencia de Zanetti en la Federación de Bibliotecas Populares de Córdoba, a la organización del Primer Congreso de Bibliotecas Populares de la Argentina (1948) y a la difusión emprendida por la revista Vida Bibliotecaria, que tuvo a Zanetti como director.

El acervo documental del CeDInCI también conserva tres grandes fondos personales que contienen varios documentos reformistas: el Fondo de Juan Antonio Solari (1899-1980), el de Herminia Brumana (1897-1954) y el de Liborio 
Justo (1902-2003) (http://archivos.cedinci.org/index.php/juan-antonio-solarifondo, http://archivos.cedinci.org/index.php/herminia-brumana-fondo y http:// archivos.cedinci.org/index.php/liborio-justo-fondo). Los dos primeros Fondos fueron donados durante la última década por dos nietas de ambos, Heminia y Ada Solari, mientras que el de Justo fue llegando al CeDInCI entre 2016 y 2018, junto a la biblioteca personal por la donación de su hija Mónica Justo. En este último Fondo se conservan algunos manuscritos inéditos en los que Justo insisten en la presencia de una inicial fracción estudiantil radicalizada, que simpatizaba con la Revolución Rusa y el comunismo y en un balance decepcionante de la misma. Además, otros documentos permiten precisar rasgos de la Facultad de Medicina de la Universidad de Buenos Aires, a la que aquel ingresó en 1919.

Si las referencias a esa fracción radicalizada ponen de manifiesto el injustificado olvido historiográfico que predominaba hasta hace muy poco sobre esa fracción, varios documentos de los Fondos de Solari y de Brumana aportan mayores precisiones sobre ello y señalan otro olvido: la vinculación que en esos inicios algunos reformistas tramaron con el movimiento feminista. Es que los volantes, afiches, recortes periodísticos y revistas que conservaron Solari y Brumana muestran que entre 1919 y 1922 una veintena de estudiantes porteños se vincularon a la fracción radicalizada del Partido Socialista y a la FUA en un fracasado intento -en el que participaron Bermann y Barros, entre otros- de ligar la Reforma a las tendencias revolucionarias del momento. Y entre esas tendencias se encontraba el "contrafeminismo del feminismo", que tendría en Brumana a una de sus plumas más mordaces, así como el "feminismo socialista" de Alicia Moreau (1885-1986) y Enrique del Valle Iberlucea (1877-1921). 
Imagen 5: Afiche de una velada y conferencia organizada por el Centro Socialista a beneficio por partes iguales de la biblioteca popular Pigüé, donde actuaba Brumana, y del periódico Bases, que dirigía Solari.

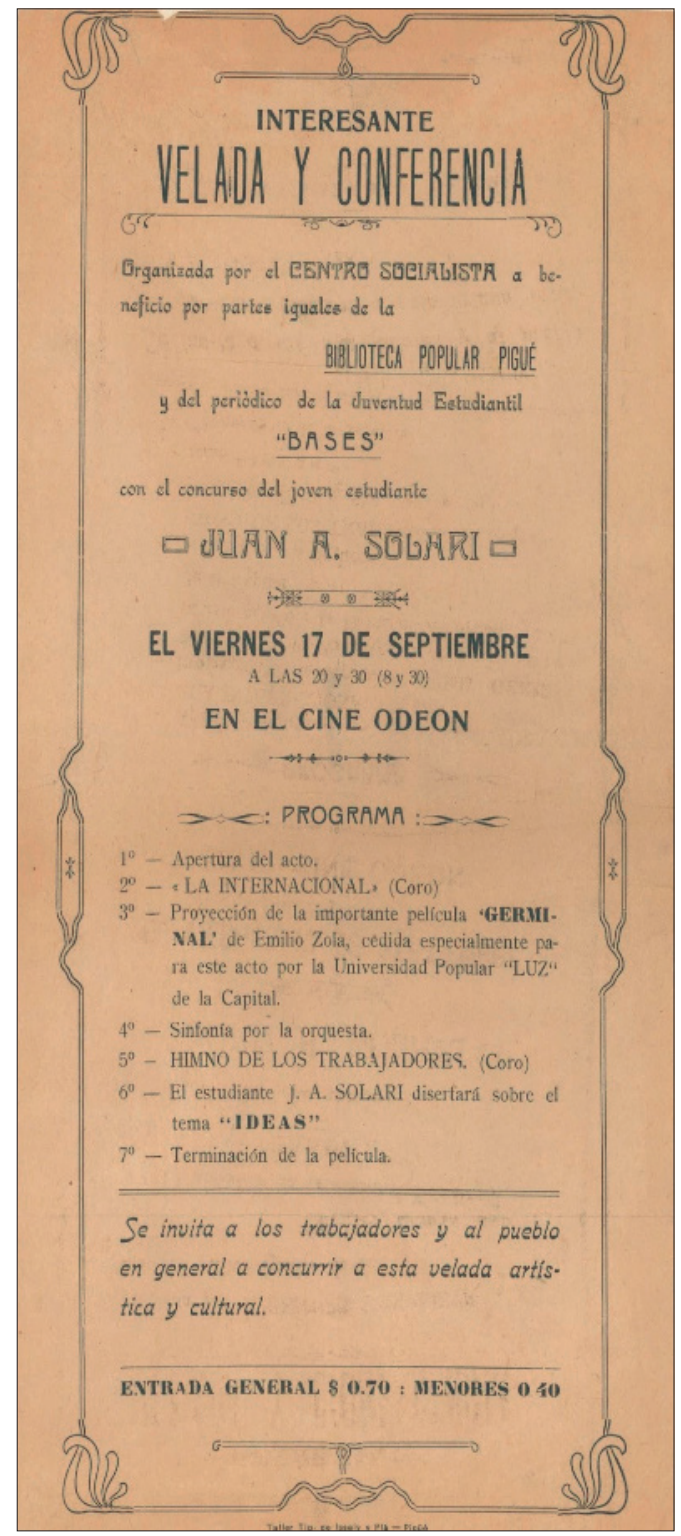

Fuente: Fondo Juan Antonio Solari. CeDInCI. http://exhibiciones.cedinci.org/ exhibits/show/reforma_universitaria/item/4350 
Embarcado en ese intento, el primero de mayo de 1919 Solari ponía a circular Bases. Tribuna de la juventud (1919-1920). Sus ocho números despliegan una prosa sarcástica que busca evitar que los estudiantes de Buenos Aires sigan simpatizando con un nacionalismo jerarquizante de la Liga Patriótica. Frente a los "hombres del orden", los jóvenes no deberían temer ser acusados de "agitadores profesionales" y tendrían que sumarse a la fracción radicalizada de la Reforma. Pero, en realidad, fue Brumana la que introdujo ese tipo de sarcasmo en Bases por Brumana, pues en el segundo número se dirigió a las maestras para exigirles que, en lugar de cursar el magisterio para conseguir un mejor marido, se comprometan en la "enseñanza del ideal”. Una exigencia que despertó una breve polémica.

Imagen 6: Polémico artículo de Hermina Brumana aparecido en el segundo de los ocho números de Bases. Tribuna de la juventud.

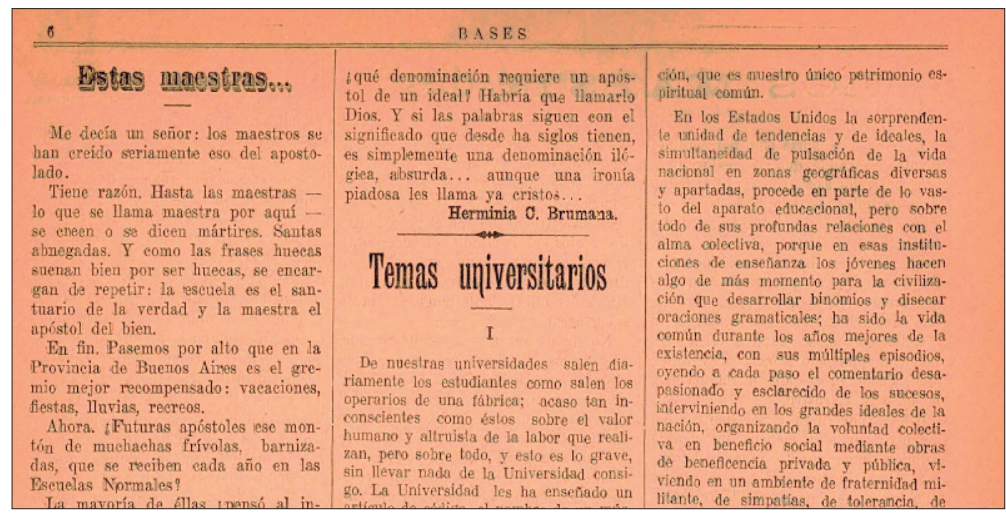

Fuente: Fondo Juan Antonio Solari. CeDInCI. http://americalee.cedinci.org/portfolio-items/bases/

Más documentos relativos al reformismo de la Facultad porteña de Derecho de la década del veinte y treinta provienen del Fondo de Héctor Raurich (19031963), una figura clave en la fundación del mítico Partido Unión Reformista Centro-Izquierda (http://archivos.cedinci.org/index.php/fondo-hector-raurich). Entre los documentos sin catalogar que llegaron por la donación de Isay Klasse y Saúl Chernikoff se encuentran folletos procedentes y originales manuscritos de distintas conferencias, apuntes sobre temas filosóficos y recortes periodísticos, que incluyen temas vinculados a la universidad. Lamentablemente, las cartas del Fondo quedaron en manos del donante, que falleció hace unos años. De haberse preservado, serían de gran interés por el amplio periplo político- intelectual de 
Raurich desde el grupo Insurrexit hasta el "entrismo" en el PS, pasando por el Partido Comunista, su fracción chispista y el trotskismo. Otros importantes documentos relativos a la pervivencia y mutación del reformismo fueron reunidos por el dirigente cordobés Pascual Bianconi (http://archivos.cedinci.org/index. php/fondo-pascual-bianconi). Su Fondo fue donado por el historiador Roberto Ferrero y se compone de cartas, artículos y volantes referidos el movimiento estudiantil cordobés entre la década de 1950 y la de 1970.

Terminemos este recorrido por los fondos reformistas del CeDInCI con el fondo que seguramente ofrezca la documentación más interesante para mostrar las profundas limitaciones que tienen las exaltaciones heroicas de unos pocos líderes: las 36 cajas del Fondo personal de José Ingenieros (1877-1925) que Diana y Horacio Valla Ingenieros donaron en 2002, una parte, y en 2008, otra (http://archivos.cedinci. org/index.php/jose-ingenieros-fondo). En cuanto a la Reforma, allí se obtiene un preciso acercamiento, por un lado, a la insistencia con que desde un comienzo algunos líderes reformistas y grupos le demandaron a Ingenieros su colocación como un maestro de la juventud y, por el otro, a la labor que este emprendió junto a un grupo de jóvenes, entre 1920 y su fallecimiento, para orientar al movimiento hacia un latinoamericanismo antiimperialista organizado en torno del boletín Renovación (1923-1930) y la Unión Latino-Americana (1925-1930). El Fondo conserva las revistas y manifiestos que pequeños y lejanos grupos le enviaban a Ingenieros en busca de consejos, los primeros escritos de Ingenieros sobre las universidades y la Reforma así como la correspondencia a través de la que los jóvenes le solicitaban el envío de textos o lo saludaban por sus discursos y publicaciones.

\section{PALABRAS FINALES}

La Reforma estallaba en Córdoba el 15 de junio de 1918. Mediante una maniobra fraudulenta, la fracción de profesores que se negaba a renovar la Universidad conseguía que su candidato, el dr. Antonio Nores, fuera elegido rector. Pero los reformistas irrumpían en el salón rectoral, impedían que se firmara el acta que legalizaba esa elección y, sin saberlo, iniciaban un movimiento de alcance latinoamericano que referenciándose en la revuelta cordobesa reclamaría la democratización de las universidades y una identidad izquierdista de los estudiantes.

Sobre el estallido de la Reforma, refiere del Mazo en su autobiografía:

Los telegramas oficiales y particulares de los amigos de Córdoba comenzaron a llegar al día siguiente, 16. Literatura típicamente romántica. Todo el día me lo pasé telefoneando y telegrafiando a 
estudiantes dirigentes, instándolos a la necesidad de la reunión en mi casa, el día siguiente quedamos comprometidos a pensar en las líneas generales de la organización y gobierno de la Universidad que queríamos levantar. (del Mazo, Vida de un político 85)

En las páginas anteriores vimos que ese compromiso de pensar y organizar colectivamente una nueva universidad estuvo acompañado de una tenaz voluntad de preservar la memoria del movimiento y que lamentablemente las generaciones siguientes no asumieron la responsabilidad de resguardar ese patrimonio y asegurar su acceso público. Si, junto a los programas para una reforma universitaria, los iniciadores del movimiento conservaron muchos de esos telegramas que del Mazo recuerda sesenta años después, su autobiografía es una forma de completar esa memoria, pues entre otras cosas menciona las llamadas telefónicas y reuniones de las que hay escasos indicios en los fondos personales.

Alejándonos de la centralidad del yo a las que podrían invitar los fondos generados por líderes de la Reforma, en el presente artículo buscamos analizar, caracterizar, y problematizar esos fondos en los cruces que presentan con otros fondos, en los proyectos comunes que muestran, y sobre todo en los itinerarios similares o contrastantes entre líderes y animadores reformistas. El análisis comparado pone de manifiesto prácticas presentes en otros militantes de izquierda, entre ellas la costumbre de armar y recortar entrevistas o artículos periodísticos sobre un tema de interés y organizar con ellos dossier temáticos. En nuestro caso, la mayoría de los fondos contienen carpetas con recortes sobre las instituciones universitarias y su organización. Esas carpetas nos permiten conocer los materiales de referencia que utilizaron los generadores de los fondos cuando prepararon conferencias o escribieron notas, pero también nos ofrecen pistas sobre revistas y otras publicaciones que no han sido resguardadas por ninguna institución. Otro amplio campo de análisis se abre en la vinculación de los documentos de los fondos personales con los fondos de tipo institucional alojados en facultades y rectorados -y que desafortunadamente no siempre se preservan siguiendo una lógica archivística ni están catalogados y disponibles a la consulta-. Los documentos de esos fondos tan distintos permiten conocer las diferencias entre los proyectos universitarios presentados y los aprobados, así como los legajos de los reformistas en su condición no de militantes sino de estudiantes y/o profesores.

Insistiendo, una vez más, en la importancia de preservar los fondos de los reformistas, de lograr que sean de acceso público y de cruzar sus documentos, cerremos el recorrido con dos documentos del Fondo Ingenieros. No solo los veinteañeros como del Mazo recibían telegramas durante ese agitado mes de junio de 1918. Ingenieros, ya un médico y científico de prestigio internacional, 
que contaba con cuarenta años, recibió algunos de ellos. En su Fondo se conserva uno muy breve, fechado el 18 de junio, en el que, en nombre de la Federación Universitaria de Córdoba, Barros lo convocaba a enviar su palabra de aliento a una juventud que declaraba estar iniciando una "cruzada redentora".

Imagen 7: Telegrama de Enrique Barros a José Ingenieros, 18 de junio de 1918.

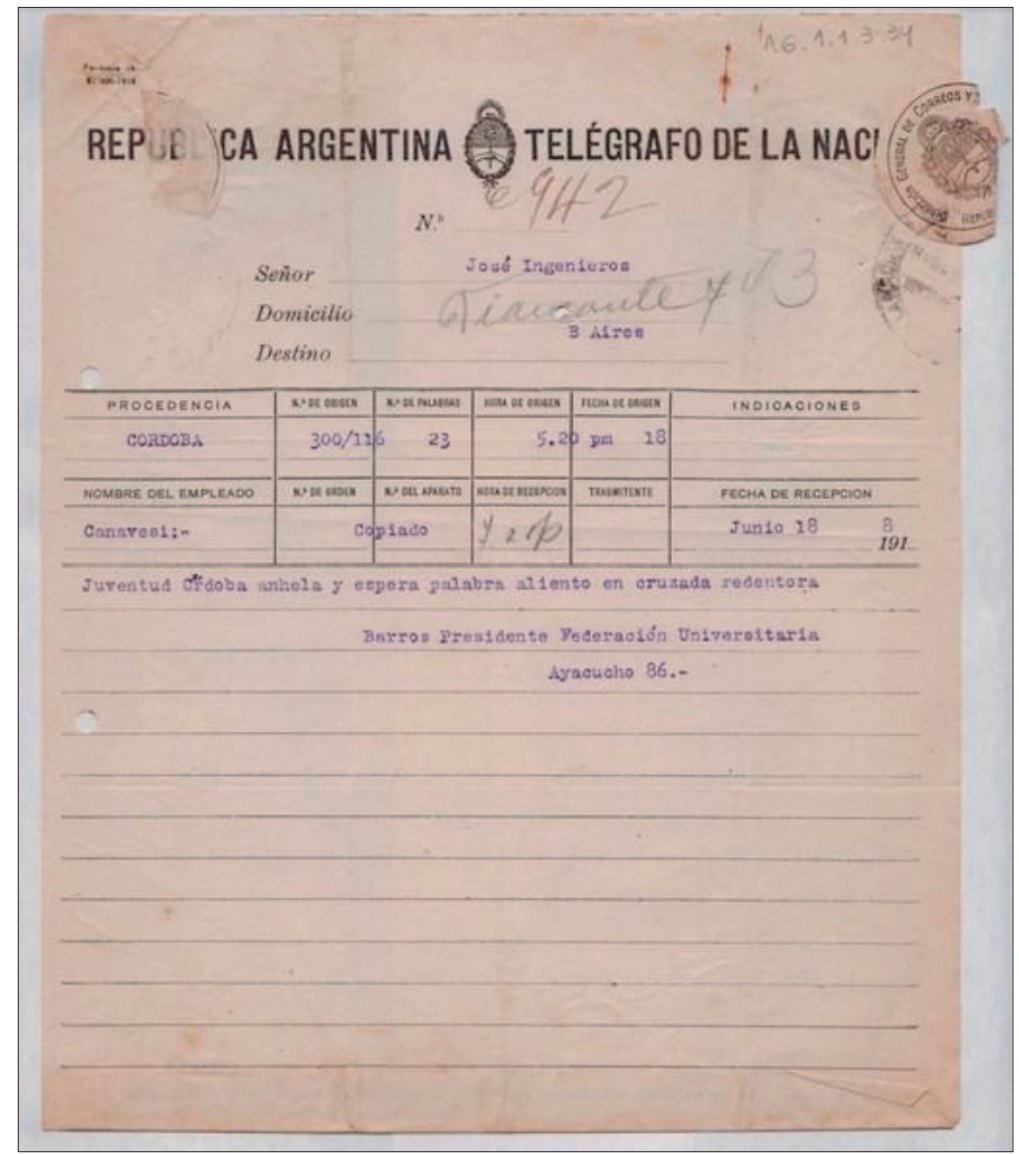

Fuente: Fondo José Ingenieros. CeDInCI.

Por las páginas de la publicación que dirigía Ingenieros, Revista de Filosofía, y del boletín que alentaba, Renovación, así como por el libro Los tiempos nuevos que editó en 1921, sabemos que Ingenieros le ofreció a esa juventud más que una palabra de aliento. Pero son las cartas, los programas, los 
volantes y las revistas estudiantiles que conservó Ingenieros -así como del Mazo, Bermann, Florentino y otros que en 1918 tenían veinte años y eran estudiantes filiados a la cultura de izquierdas- los que nos permiten conocer cómo se tramó esa vinculación intergeneracional, la sensibilidad política común de la que partió, y las bifurcaciones que ella recorrió, las múltiples tareas involucradas, así como el sistema sexo-genérico y los afectos en los que se apoyó.

Algunas precisiones se advierten en las cartas que Ingenieros recibió de Bermann, una vez que este fijó su residencia en Córdoba. Desde entonces Bermann devino el enlace de los reformistas cordobeses con el maestro porteño. Además de pedirle consejos sobre la posición a asumir en la coyuntura antirreformista nacional abierta en 1923, le insistió, sin éxito, en que aceptara ser el candidato reformista a rector de la Universidad Nacional de Córdoba. Y en la carta del 17 de febrero de 1924, Bermann nos ofrece una interesante síntesis de las tareas que componían la militancia reformista y la camaradería que las hacía posible. Le escribe a Ingenieros: “¿No quiere ser Rector Cordobensis [sic], aunque más no sea por unos meses, para regocijarse con sus doctores [...] Decídase a ser Rector Cordobés y presentaré su candidatura". La carta se compone de dos pequeñas carillas, pero ello no impide que la convocatoria a rector esté acompañada por: el agradecimiento a la atención que Ingenieros le dio a una paciente que aquel le había enviado; el aviso de que lo visitaría otro médico que ejercía una militancia reformista clave en Córdoba, el fisiólogo pacifista judeoalemán Georg Nicolai (1874-1964); la propuesta de que publique un libro de Nicolai en el sello de la Revista de Filosofía que dirigía Ingenieros; el recuerdo de una polémica en la que intervino otro profesor reformista cordobés, el abogado y sociólogo Raúl Orgaz (1888-1948); y, también, las felicitaciones a una crítica que Ingenieros publicó sin firma en Renovación. 
Imagen 8: Carta mecanografiada de Gregorio Bermann a José Ingenieros, 17/06/1924.

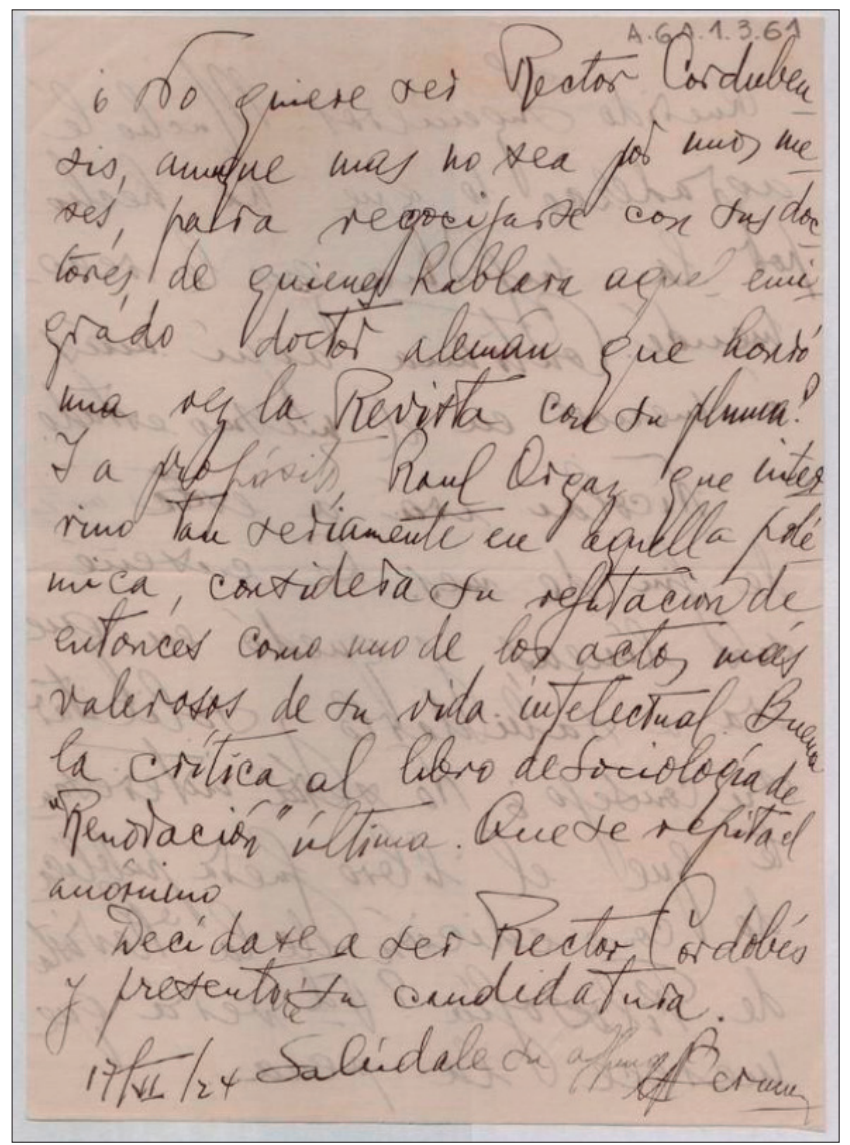

Fuente: Fondo José Ingenieros. CeDInCI.

En definitiva, la recuperación de los fondos de los reformistas y un análisis atento de los cruces y contrastes entre ese tipo de fondos, por un lado, y los de las instituciones universitarias, por el otro, es fundamental para explorar el modo de ser universitario que inauguró la Reforma Universitaria. Según sintetiza la carta de Bermann, ese modo colocó en un lugar decisivo el ejercicio serio de la profesión, el compromiso con los problemas sociales, la amistad entre reformistas y la edición de revistas, libros y boletines. El recorrido por los documentos del Fondo Ingenieros y de los fondos de algunos reformistas nos permite agregar que también fueron centrales la publicación de artículos, 
manifiesto, volantes y afiches, la elaboración de programas de renovación de las facultades y la fundación de federaciones y asociaciones, y también que el divorcio y otros reclamos ligados a la "cuestión femenina", que en un principio se cruzaron con la Reforma, pronto quedaron desplazados.

Sin duda, cada fondo responde a decisiones e intereses que requieren un análisis detenido y sus ausencias o excesos difícilmente coinciden con las expectativas de quienes van en su búsqueda. A pesar de ello, la preservación de una compleja memoria político-cultural puede reconocerse como la lógica general desde la que los líderes y animadores de la Reforma acopiaron documentación. Esa lógica archivística de carácter "militante" dispuso que se conservaran todos esos papeles, no solo para que las investigaciones históricas tuvieran disponible un archivo, sino sobre todo para asegurar que, generación tras generación, perviviera la voluntad reformista de democratizar las universidades y las sociedades. Un siglo después, se ha conservado muy poco de esa multifacética memoria. Y uno de los desafíos que se le presenta al diálogo entre la archivística, la historia y la política es que no queden dudas de que los cajones de papeles que durante décadas guardaron los reformistas y hoy se encuentran arrumbados y en posesión de particulares son parte del patrimonio político-cultural y, por ello, deben tener asegurada su pervivencia y su puesta a la consulta pública. 


\section{REFERENCIAS BIBLIOGRÁFICAS}

Artières, Philippe. "Arquivar a própria vida." Revista Estudos Históricos, vol. 11, no. 21, julio de 1998, pp. 9-34. http://bibliotecadigital.fgv.br/ojs/ index.php/reh/article/view/2061.

Artières, Philippe, y Dominique Kalifa. "El historiador y los archivos personales: paso a paso". Políticas de la Memoria, no. 13, 2013, pp. 7-11. http://ojs.politicasdelamemoria.cedinci.org/index.php/PM/ article/view/133.

Belloto, Heloísa Liberalli. "Arquivos pessoais em face da teoria arquivística tradicional: debate com Terry Cook". Revista Estudos Históricos, vol. 11, no. 21, julio de 1998, pp. 201-08. http://bibliotecadigital.fgv.br/ojs/ index.php/reh/article/view/2063.

Brothman, Brien. "The Past That Archives Keep: Memory, History, and the Preservation of Archival Records". Archivaria, vol. 51, no. 0, enero de 2001, pp. 48-80. https://doi.org/10.14404/jksarm.2014.14.4.099

Bustelo, Natalia. "Derecho, extensión universitaria y revolución social. La Reforma Universitaria en la Facultad de Derecho y Ciencias Sociales de la Universidad de Buenos Aires (1918-1930)". Conflicto Social, vol. 9, no. 16, diciembre de 2016, pp. 60-90. https://doi. org/10.35537/10915/53576

Caimari, Lila M. La vida en el archivo: goces, tedios y desvíos en el oficio de la historia. Siglo Veintiuno Editores, 2017. https://doi.org/10.4067/s071823762019000200253

Celentano, Adrián. 1938: Reforma universitaria, higiene social y antifascismo en la UNLP: CeDInCI, Arte editorial Servicoop, 2019.

Celentano, Adrián, y Natalia Bustelo. "Presentación de "Estudiantes y populismo" de Juan Carlos Portantiero." Los Trabajos y los Días, noviembre de 2012, pp. 87-93. revistas.unlp.edu.ar, https://revistas.unlp. edu.ar/LosTrabajosYLosDias/article/view/5751.

Cook, Terry. "Arquivos pessoais e arquivos institucionais: para um entendimento arquivístico comum da formação da memória em um mundo pósmoderno". Revista Estudos Históricos, vol. 11, no. 21, julio de 1998, pp. 129-50. https://doi.org/10.5007/2175-7976.2008v15n20p307

Cúneo, Dardo (comp.). La Reforma Universitaria. Ayacucho, 1988.

De Castro Gomes, Angela Maria. "Nas malhas do feitiço: O historiador e os encantos dos arquivos privados". Revista Estudos Históricos, vol. 11, no. 
21, julio de 1998, pp. 121-28, http://bibliotecadigital.fgv.br/ojs/index. $\mathrm{php} / \mathrm{reh} /$ article/view/2069.

Del Mazo, Gabriel. La Reforma Universitaria. Centro de Estudiantes de Medicina de la Universidad de Buenos Aires, Federación Universitaria Argentina, 1926. https://doi.org/10.19137/pys-2019-260206

---. La Reforma Universitaria. Centro de Estudiantes de Ingeniería, 1941.

---. Vida de un político Argentino: convocatoria de recuerdos. Plus Ultra, 1976.

Domínguez Rubio, Lucas. El anarquismo argentino. Bibliogragfia, hemerografía y fondos de archivo. CeDInCI-Anarres, 2018.

Douglas, Jennifer. Archiving authors: rethinking the analysis and representation of personal archives. University of Toronto, 2013. https://tspace.library. utoronto.ca/bitstream/1807/35808/1/Douglas_Jennifer_L_201306_ PhD_Thesis.pdf

Duby, Georges, et al., editores. Historia de las mujeres en Occidente. Taurus.

Farge, Arlette. La atracción del archivo. Edicions Alfons el Magnànim, Institució

Valenciana d'Estudis i Investigació, 1991. https://doi.org/10.1017/ s0212610900003475

Fernández Cordero, Laura. "Fondos personales en el Programa Sexo y Revolución. Memorias políticas feministas y sexo-genéricas del CeDInCI". II Jornadas / Primer Congreso Internacional "Los archivos personales, prácticas archivísticas, problemas metodológicos y usos históriográficos", Buenos Aires, CeDInCI, 2018, pp. 18-36, http://cedinci.unsam.edu.ar/pdf/jornadas/ActasArchivos-Personales.pdf

Foro Internacional Memoria e Historia. ¿Por qué recordar? : Foro Internacional Memoria e Historia : Unesco, 25, marzo, 1998, La Sorbonne, 26, marzo, 1998. Granica, 2002. /z-wcorg/.

Foucault, Michel. La vida de los hombres infames. Altamira, 2006.

---. Los anormales: curso en College France (1974 - 1975). Fondo de Cultura Económica, 2000.

---. Vigilar y castigar: nacimiento de la prisión. Siglo Veintiuno, 2008.

Ginzburg, Carlo. El queso y los gusanos: el cosmos según un molinero del siglo XVI. Ariel, 2016. https://doi.org/10.14409/dys.v1i11/12.5817

Grancelli Chá, Néstor. Eslabones de militancia. Claridad, 2011.

Heredia Herrera, Antonia. "La Archivística, a debate". Anuario Escuela de Archivología, no. 3, noviembre de 2012, pp. 7-26. revistas.unc.edu.ar, 
https://revistas.unc.edu.ar/index.php/anuario/article/view/12484.

---. ¿Qué es un archivo? Trea, 2007.

Hobbs, Catherine. "The Character of Personal Archives: Reflections on the Value of Records of Individuals". Archivaria, vol. 52, no. 0, febrero de 2001, pp. 126-35. https://doi.org/10.14404/jksarm.2014.14.4.099

Jardim, Jose Maria. Políticas y sistemas de archivos. Secretaría General Iberoamericana, 2010. Open WorldCat, http://archivosiberoamericanos. org/wp-content/uploads/2012/09/Pol\%C3\%ADticas-y-Sistemas.pdf.

Lazarte, Juan. Líneas y trayectoria de la Reforma Universitaria. Librería Ruiz, 1935.

Nazar, Mariana. "Archivos, memoria y derechos: reflexiones en torno al caso argentino". Comma, vol. 2010, no. 2, enero de 2010, pp. 145-58. https:// doi.org/10.3828/comma.2010.2.12

Petra, Adriana. "Los documentos particulares como fuentes históricas: la experiencia del CeDInCI con los fondos de archivo de las izquierdas argentinas". Políticas de la Memoria, no. 6/7, diciembre de 2007, pp. 206-11. https://doi.org/10.4185/rlcs-2016-1084

Petrucci, Armando. Escribir cartas. Una historia milenaria. Ampersand, Buenos Aires, 2018. https://doi.org/10.19137/circe-2019-2301010

Plummer, Ken. Los documentos personales: introducción a los problemas y la bibliografia del método humanista. Siglo Veintiuno, 1989.

Pons, Anaclet. "La memoria digital del mundo. Los historiadores y el archivo". Tábula, vol. 0, no. 21, enero de 2019. publicaciones.acal.es, http:// publicaciones.acal.es/index.php/tabula/article/view/696.

Portantiero, Juan Carlos. Estudiantes y política en América Latina: El proceso de la reforma universitaria (1918-1938). Siglo XXI, 1978.

Prochasson, Christophe. "Atenção: verdade! Arquivos privados e renovação das práticas historiográficas”. Revista Estudos Históricos, vol. 11, no. 21, julio de 1998, pp. 105-20, http://bibliotecadigital.fgv.br/ojs/index.php/ $\mathrm{reh} / \mathrm{article} / \mathrm{view} / 2064$.

Swiderski, Graciela. Las huellas de Mnemosyne: la construcción del patrimonio documental en la Argentina. Editorial Biblos, 2015.

Tarcus, Horacio. "Dí tu palabra y rómpete: el corto verano del Grupo Universitario Insurrexit y su revista". Dimensiones del reformismo universitario, compilador Alejandro Eujanian, Rosario, HyA-UNR, 2018, pp. 95-135.

---. “¿El drenaje patrimonial como destino? Bibliotecas, hemerotecas y archivos argentinos: un caso de subdesarrollo cultural." La Biblioteca, no. 1, 2005 
de 2004, pp. 28-37.

---. "Los archivos del movimiento obrero, los movimientos sociales y las izquierdas en la Argentina": Políticas de la Memoria, no. 10/11/12, 2011, pp. 7-20. https://doi.org/10.4067/s0718-50492018000700114

---. Diccionario biográfico de la izquierda argentina de los anarquistas a la "nueva izquierda", 1870-1976. Emecé, 2007. 